\title{
A FAMILIAL HEART DISEASE
}

\author{
BY \\ L. G. DAVIES \\ From the Cardiff Royal Infirmary, Cardiff \\ Received August 22, 1951
}

The description of familial cardiomegaly by Evans (1949) has thrown some light on the group of patients in whom cardiac enlargement, for which there appears to be no adequate clinical explanation, is the main physical finding. The purpose of this paper is to describe a family showing evidence of a cardiac abnormality affecting five of nine siblings and one of their children. When the first member of the family was seen and the history considered, familial cardiomegaly was regarded as the probable diagnosis. However, the results of post-mortem examinations on two sisters were traced and it seems that the condition, though related to this, includes some degree of subaortic stenosis.

\section{CASE REPORTS}

Case 1. Woman, aged 40 years. She complained of some shortness of breath for the last six years while going quickly upstairs or uphill but this had not become any worse. During the same period she had noticed palpitation which always started and stopped abruptly and lasted for only a few minutes. These attacks occurred two or three times a week and would often awaken her at night. There was no history of rheumatic fever or chorea.

Her father, mother, four brothers and one sister were alive and well. Three sisters had died, all of them suddenly, and one was known to have had an enlarged heart.

On examination. Average general condition, lean build. Pulse regular, 70 a minute. Blood pressure, 125/65. Apex beat $9 \mathrm{~cm}$. from midline. No thrills; a soft systolic murmur heard between apex and sternum; heart sounds otherwise normal. Electrocardiogram (Fig. 1) early left ventricular hypertrophy, with frequent long periods of nodal rhythm (Fig. 3A), that were regular and at a rate slightly slower than sinus rhythm. Screening, general cardiac enlargement with a normal aortic knuckle (Fig. 5). Other systems normal. Blood count: red cells 4,130,000, Hb $10 \cdot 6 \mathrm{~g}$. (73\%). Blood cholesterol normal.

In view of these findings an effort was made to trace the medical history of each of the three dead sisters and the information obtained is as follows.

Case 2. Woman, aged 38 years (died 1944). She had always been thought to be healthy but had attended her doctor for a few weeks before death for "nervous debility"; a rapid pulse had been noted. She collapsed while out walking and died immediately.

Necropsy. External appearance-general nourishment good, post mortem lividity intense. Pericardium normal, heart weight $340 \mathrm{~g}$. (body weight $54 \mathrm{~kg}$.) Marked relative dilatation of mitral valve; cusps of all valves normal. In left ventricle, on upper part of interventricular septum, behind the aortic cusp of the mitral valve, an area of fibrosis some $4 \mathrm{~cm}$. square, with a raised ridge along its lower border. Left ventricle dilated and moderately hypertrophied. Left atrium and right ventricle dilated and hypertrophied. On microscopic examination, marked fibrosis of myocardium. Only other noteworthy findings, some bilateral bronchiectasis and a nodular colloid goitre.

Conclusion: fibrosis of myocardium and subaortic stenosis.

Case 3. Woman, aged 29 years (died 1943). For a week prior to death she had complained of some palpitation. She visited her mother on the afternoon of her death and seemed to be in good health. Her mother left her sitting in the kitchen while she went into the garden for a few minutes. When she came back her daughter was sitting in a chair unconscious; a doctor was called and found her to be dead. 


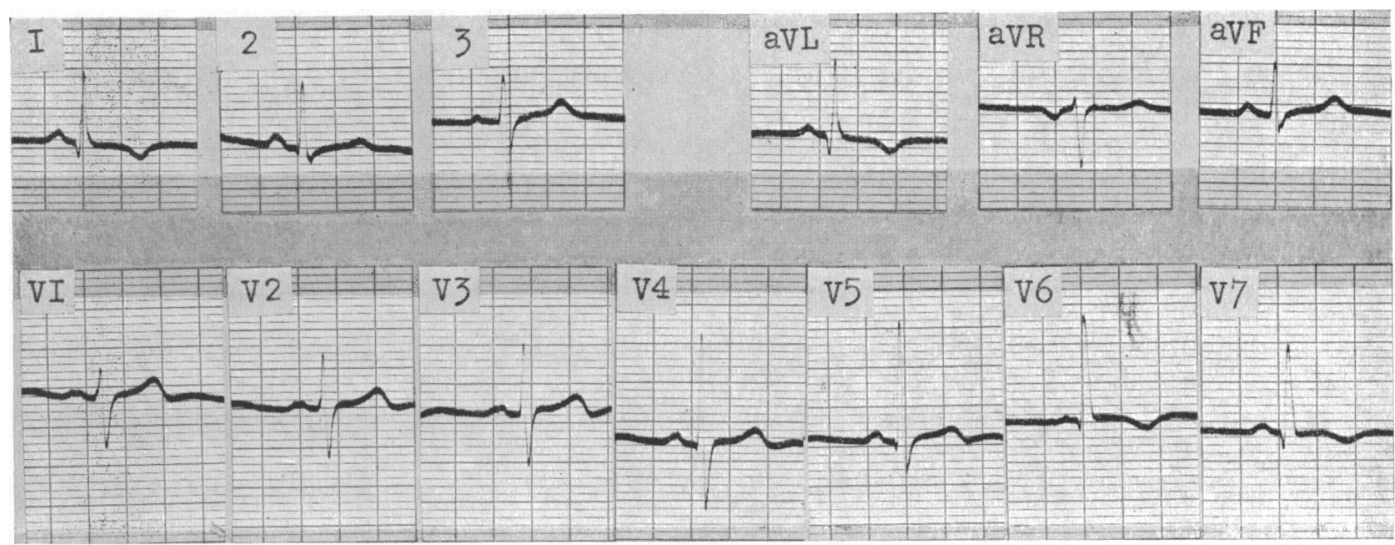

Fig. 1.-Electrocardiogram from Case 1. Woman, aged 40 years.

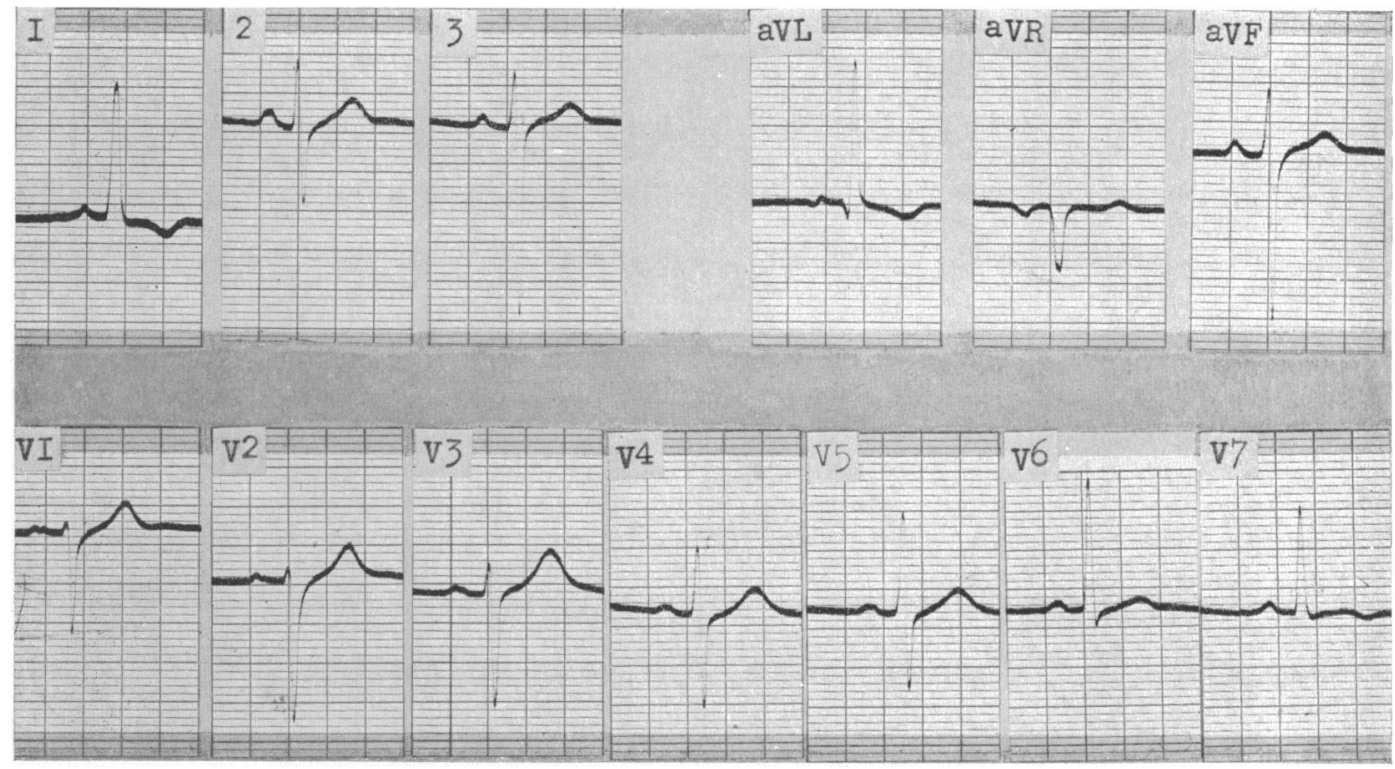

Fig. 2.-Electrocardiogram from Case 5. Man, aged 27 years.

Necropsy. Externally, body well nourished. Some fluid in pericardium, heart much enlarged $(440 \mathrm{~g}$.), left ventricle very much hypertrophied; aorta small. The recorded opinion of the police surgeon was " death from syncope due to aortic stenosis." Unfortunately there is no description of the nature or degree of the aortic stenosis.

Case 4. Woman, aged 16 years (died 1931). She was thought to be healthy but had been ill with asthma and bronchitis for a few weeks before death. She was given an injection for her asthma and died suddenly ten or twenty minutes later. No post-mortem examination was made. The certified cause of death was (a) dilatation of heart, and $(b)$ acute bronchitis and asthma. Her practitioner does not remember the patient and the nature of the injection is not known.

Case 5. Man, aged 27 years. The fourth brother had always been fit and healthy and served in North Africa in a tank recovery team. He had been on many battle courses and had never noticed anything unusual. He now drives a lorry and helps to load and unload it. 


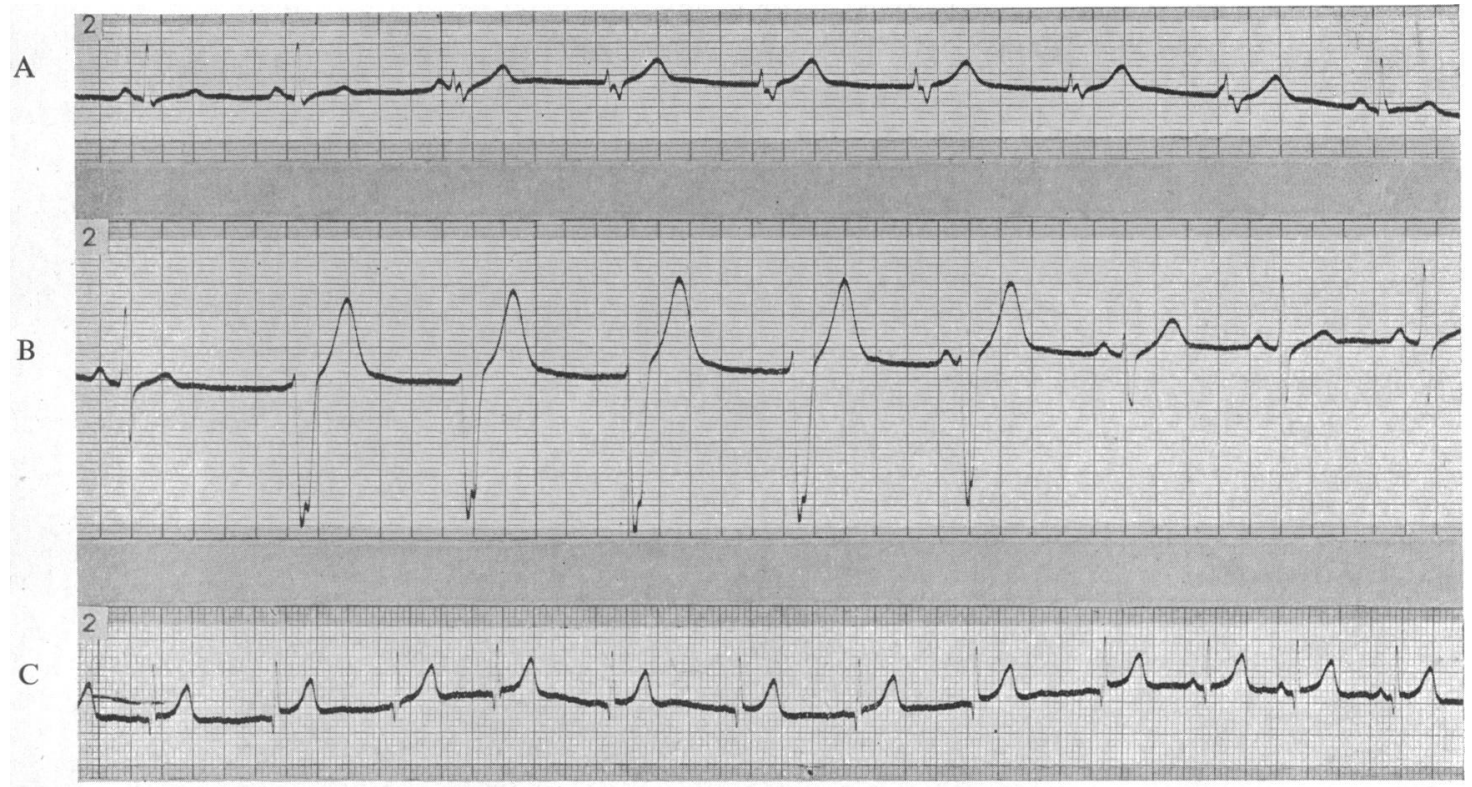

Fig. 3.-(A) Electrocardiogram from Case 1, woman, aged 40 years. (B) from Case 5, man, aged 27 years.

(C) from Case 6, boy, aged 3 years. All three tracings are standard lead II.

On examination. Good general condition. Pulse regular, 80 a minute. Blood pressure 120/70. Apex beat $12 \mathrm{~cm}$. from mid line. Cardiac impulse forceful; no thrills. Systolic murmur heard between apex and sternum; heart sounds otherwise normal. Other systems normal.

The electrocardiogram (Fig. 2) showed a similar pattern to Fig. 1, with similar conduction defects (Fig. 3B). Nodal systoles of different types were seen (Fig. 4). Screening showed considerable cardiac enlargement with particular involvement of the left ventricle; the aortic knuckle was small (Fig. 6).

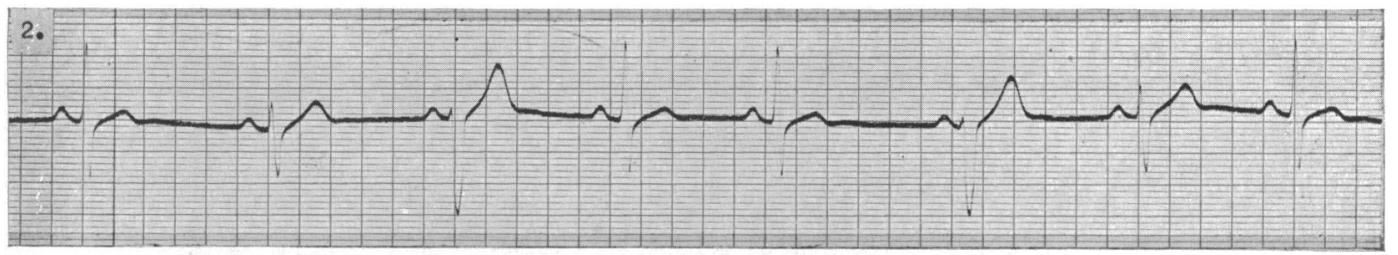

FIG. 4.-Electrocardiogram from Case 5, man, aged 27 years, showing varying nodal complexes.

The remaining sister (aged 31 years) and three of the four brothers (aged 29, 38, and 49 years) showed no cardiac or other abnormality on examination.

Of the nine siblings, therefore (Fig. 7), two with cardiomegaly are alive (Cases 1 and 5) and three thought to be healthy had died suddenly at comparatively early ages. Post-mortem examinations on two of these had shown a cardiac abnormality that had caused death. The parents are alive and well but refuse to be examined; they are unrelated. The father (aged 71 years) was an inpatient in another hospital in 1949 with " acute gastritis"; there is no record in his notes of any cardiac abnormality; a barium meal examination was made but it is not known if the chest was screened, and no chest film was taken. The mother is aged 73 years; her parents lived to a good age (father 69 years, mother 85 years). Of the paternal grandparents, the mother was over 70 years old when she died, but the father died suddenly at the age of 38 years. 


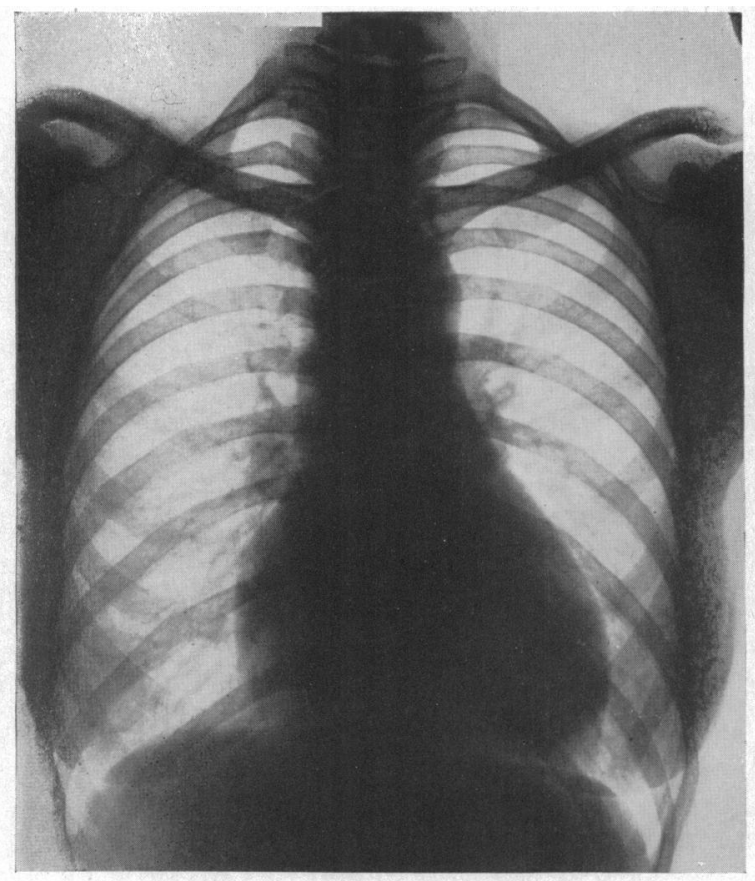

Fig. 5.-Teleradiogram from Case 1, woman, aged 40 years.

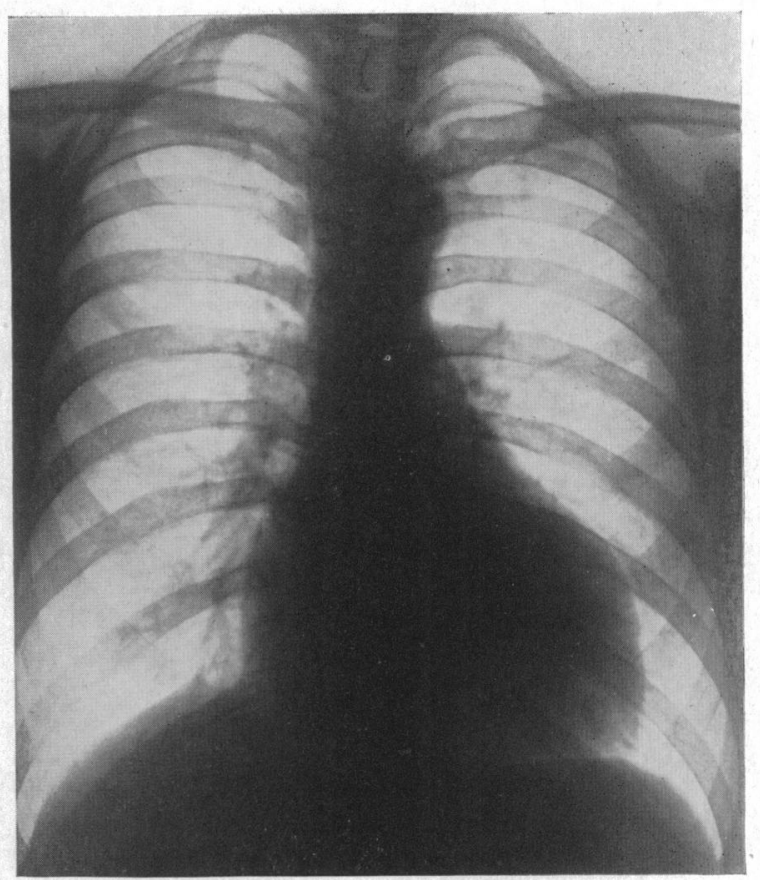

Fig. 6.-Teleradiogram from Case 5, man, aged 27 years.

The generation now under study has had fourteen children, one (a male twin) was found dead in bed at the age of two months - certified cause "convulsion due to congenital debility." The other thirteen are alive, have been examined clinically, radiologically, and electrocardiographically. In only one child has any abnormality been found (Case 6). There was one grandchild who died at the age of three months following an operation for spina bifida; the heart was found to be normal post mortem.

Case 6. Boy, aged 3 years. This boy is the third son of the first patient (Case 1) who says that often when she picks him up she notices that his heart is beating irregularly though not at a fast rate.

On examination. Average general condition. Pulse regular. Heart was not enlarged clinically. Systolic murmurs between apex and sternum; heart sounds otherwise normal. Electrocardiograms, taken on several occasions, show intervals of nodal rhythm though the QRS complexes do not change in form (Fig. 3 C). On screening, cardiovascular outline full sized but not outside normal limits.

\section{DISCUSSION}

The same inherited abnormality is believed to be present in each instance; the familial incidence and the history of sudden death at an early age from an unsuspected heart condition is suggestive. The affected members examined (Cases 1, 5, and 6) have clinical features in common. In the adults cardiac enlargement is the main finding; in all three there are similar murmurs heard in the same area, and the cardiograms show similar conduction defects. Of the two who came to necropsy, one had a degree of subaortic stenosis, while the findings in the other case were reported in less detail and merely record aortic stenosis.

The most acceptable explanation for subaortic stenosis is that amalgamation of the bulbus cordis into the ventricles has been arrested (Keith, 1924). The classical signs were recorded by Abbott (1936) as " the absence of any systemic evidence of aortic obstruction in the presence of 


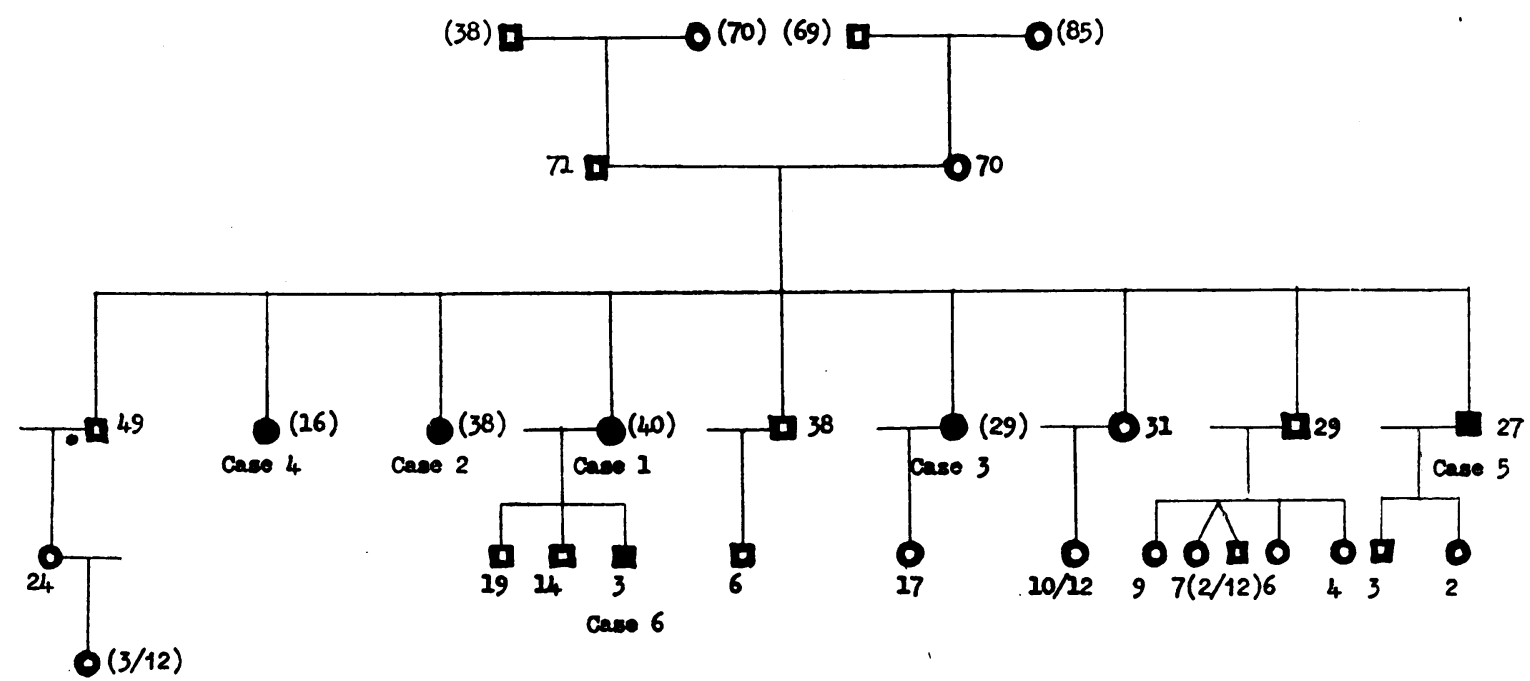

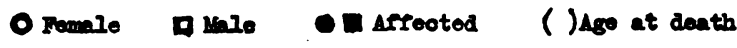

Fig. 7.-Family tree of cases discussed.

distinctive physical signs in this area." The patients examined do not show these physical findings. The macroscopic appearance of the heart in Case 2 was described in detail and there is no doubt that the subaortic stenosis was partial, a short ridge being present and not a complete ring. The signs of stenosis must vary with its degree and an incomplete stenosis would account for the relative absence of physical signs in these patients (Cases 1, 5, and 6). Equally it would explain why no cardiac abnormality had been suspected before death in the others affected. This reasoning holds for the recognition of valvular aortic stenosis, "reliance on gross signs will allow a diagnosis in only a quarter of the cases to be found post mortem " (Parkinson, 1949), and these difficulties were discussed and illustrated by Kiloh (1950).

Yet the difference between classical subaortic stenosis as previously reported and the condition described here is not merely one of degree. The former resembles other congenital heart lesions in that a familial incidence is rare. Courter $e$ t al. (1948) in a review found only 63 reports of a congenital heart condition affecting two or more members of a family. Again there is an obvious difference in prognosis: in classical subaortic stenosis " the prognosis is excellent" (Wood, 1950), "it is a relatively benign lesion" (Brown, 1950). Grishman et al. (1947) and Young (1944), however, believe the prognosis to be rather poor; the chief risk is bacterial endocarditis although syncope and sudden death are recognized.

In subaortic stenosis the usual cardiographic findings are of a sinus rhythm, left axis deviation and possibly evidence of left ventricular stress (Graybiel and White, 1947); the records illustrated here show these features. Arrhythmias, however, have not been recorded as common in classical subaortic stenosis though conduction defects occur with sufficient frequency in calcific aortic stenosis to be considered features of the disease (Friedberg, 1950).

Again, in classical subaortic stenosis the heart size is normal or there is a little left ventricular enlargement. Young (1944) reported ten examples, all healthy young men between the ages of 19 and 30 years with the classical signs but none showed clinical evidence of enlargement. It seems evident that in this family the heart size (particularly in Cases 1 and 5) could not be the result of obstruction to left ventricular outflow, and as there is no evidence of any other valvular or septal defect, the explanation must lie in the state of the myocardium.

In familial cardiomegaly, myocardial fibrosis is the histological finding, the heart size may be considerable (over $1000 \mathrm{~g}$.) and varies with the degree of fibrosis. There is only one section of 
myocardium available for comparison (from Case 2) and it is not known from which part of the ventricle it was taken but the fibrosis shown is considerable. The condition reported here has a familial distribution which is more striking than the examples of familial cardiomegaly described by Evans (1949). In addition there are clinical features that are common to both.

Arrhythmias of all types were recorded in familial cardiomegaly and indeed as might be expected from the state of the myocardium an irregular pulse was usual. These disturbances of rhythm were important in that death was caused by the onset of some type of tachycardia. It seems likely that the same is true of the condition described here. A rapid pulse had been noted in Case 2, Case 3 had complained of palpitation for a week before death, and Case 4 died after an injection-which might well have been adrenalin-for her asthma. It is unlikely that minor obstruction to aortic filling as was present in Case 2 could interfere to any appreciable degree with the coronary circulation and so cause sudden death.

When familial cardiomegaly was first described its hereditary nature was compared with that of Friedreich's ataxia. Now it was already known that in this disease cardiac lesions were not uncommon for electrocardiographic abnormalities had been described (Evans and Wright, 1942). Manning (1950) has now reported cases of Friedreich's ataxia showing cardiac abnormalities pathologically similar to those described in familial cardiomegaly. Indeed, in one patient, cardiac failure was the presenting feature and the cause of death. It was suggested that these two conditions are related ætiologically in that while the heart or central nervous system may be involved singly, both may be affected. Friedreich's ataxia is only one of a group of heredo-familial ataxias and if in these the nervous system can be involved in varying degree and with differences in detail, the heart when affected by the same agency might well show similar variation. What is rather surprising is that subaortic stenosis, though not very uncommon (Wood, 1950) and with a good expectation of life has not been recorded as a familial defect.

In the heredo-familial ataxias, symptoms and signs are as a rule present before puberty. At what age can the cardiac manifestations be diagnosed with confidence or excluded with equal confidence? This practical difficulty is illustrated by Case 6; the history of arrhythmia and the systolic murmur would mean nothing but for the family history and the finding of an occasional conduction defect. The examination of adolescents is likely to prove conclusive, but negative findings under the age of five years (as were five of the children examined) or even under the age of ten years may not be of much value, as it is possible that others of the younger generation may be affected. The family tree (Fig. 7) shows that the condition which is transmitted as a dominant character is to some extent self limiting. The three who died of it had only one direct descendant, yet pregnancy has not caused cardiac embarrassment for the first patient has had three uneventful pregnancies and Case 3 had one.

Unexplained cardiac enlargement in the young adult is not common but it is evident that close enquiry into the family history might well be helpful. There are many reports (Norris and Pote, 1946; Doane and Skversky, 1944; Whittle, 1929; Levy and von Glahn, 1937; Ware and Chapman, 1947) that refer to cardiomegaly as the main finding in subjects who died suddenly or shortly after the onset of an unexplained congestive failure. These reports must include several different conditions but the family history is not usually recorded. As symptoms are commonly absent until this terminal phase, it may be helpful to examine the relatives of a patient with unexplained cardiomegaly who dies in this way.

Treatment. The condition does not permit of cure and as for prevention we know too little about its inheritance to advise one way or the other. In the handling of the patients the psychological aspects were important and interesting. All the adults examined were aware of the high incidence of heart disease in the family and the liability to sudden death as a result of it. Those who could be assured that they had a normal heart showed considerable relief but the attitude of the parents that they "would rather not know anything about it" was understandable. One felt sorry for Case 5 who was free of symptoms but the only advice given was that he should avoid undue effort (e.g. cycling uphill). Quinidine has been given to Cases 1 and 5 in the hope that it would prevent any 
fatal burst of tachycardia; although it appeared to make arrhythmias less frequent it was difficult to get the patients to take it regularly over a long period while they were free from symptoms. A penicillin cover will be provided for any dental treatment.

\section{SUMMARY}

A family with a high incidence of heart disease is described. This is thought to be as the result of a congenital defect and there is evidence that the same condition was present in all the affected members.

The condition is compared and contrasted with subaortic stenosis and familial cardiomegaly.

In patients with obscure cardiomegaly, examinations of the relatives may yield useful information.

I wish to thank Dr. William Phillips and Professor J. Gough for their advice and encouragement and Miss C. Rumbelow for technical assistance.

\section{REFERENCES}

Abbott, M. E. (1936). Atlas of Congenital Heart Disease. The American Heart Association, New York. Brown, J. W. (1950). Congenital Heart Disease. Staples, London and New York.

Courter, S. R., Felson, B., and McGuire, J. (1948). Amer. J. med. Sci., 216, 501.

Doane, J. C., and Skversky, N. J. (1944). Amer. Heart J., 28, 816.

Evans, W. (1949). Brit. Heart J., 11, 48.

, and Wright, G. (1942). Brit. Heart J., 4, 91.

Friedberg, C. K. (1950). Diseases of the Heart. W. B. Saunders, Philadelphia and London.

Graybiel, A., and White, P. D. (1947). Electrocardiography in Practice. W. B. Saunders, Philadelphia and New York Grishman, A., Steinberg, M. F., and Sussman, M. L. (1947). Med. Clin. North America, 31, 543.

Keith, Sir A. (1924). Lancet, 1267.

Kiloh, G. A. (1950). Brit. Heart J., 12, 33.

Levy, R. L. and von Glahn, W. C. (1937). Tran. Ass. Amer. Phys., 52, 259.

Manning, G. W. (1950). Amer. Heart J., 39, 799.

Norris, R. F., and Pote, H. H. (1946). Amer. Heart J., 32, 599.

Parkinson, J. (1949). Lancet, 1, 895.

Ware, E. R., and Chapman, B. M. (1947). Amer. Heart J., 33, 530.

Whittle, C. H. (1929). Lancet, 1, 1254.

Wood, P. (1950). Diseases of the Heart and Circulation. Eyre and Spottiswoode, London.

Young, D., (1944). Amer. Heart J., 28, 440. 